\title{
Preenchimento de Falhas e Espacialização de Dados Pluviométricos: Desafios e Perspectivas
}

\author{
João Paulo Brubacher $^{1}$ (D), Guilherme Garcia de Oliveira ${ }^{1}$ (D), Laurindo Antonio Guasselli ${ }^{1}$ \\ ${ }^{1}$ Laboratório de Geoprocessamento e Análise Ambiental, Programa de Pós-Graduação em \\ Sensoriamento Remoto, Centro Estadual de Pesquisas em Sensoriamento Remoto e Meteorologia, \\ Universidade Federal do Rio Grande do Sul, Porto Alegre, RS, Brasil.
}

Recebido em: 20 de Agosto de 2019 - Aceito em: 23 de Março de 2020

\begin{abstract}
Resumo
A precipitação é uma das variáveis climáticas mais importantes para o planejamento urbano e rural, para monitorar eventos extremos que possam causar impactos na sociedade e auxiliar em projetos de drenagem urbana, a fim de reduzir os riscos inerentes a inundações e alagamentos, ou mesmo obras de engenharia, como dimensionamento de barragens. No entanto, as falhas em séries extensas prejudicam esses estudos, sendo necessário utilizar modelos para o seu preenchimento. O presente estudo tem como objetivo revisar os métodos de preenchimento de falhas e de interpolação espacial de dados de precipitação. A revisão dos métodos foi realizada a partir da pesquisa e leitura de materiais bibliográficos, de modo a conceituar as abordagens, identificar vantagens e desvantagens de cada método e apresentar como estudos recentes, nacionais e internacionais, têm inovado ao comparar o desempenho em diferentes áreas de estudo. Com base nessa revisão, os principais métodos para o preenchimento de falhas são os seguintes: i) ponderação a partir de Regressão Linear Simples ou Múltipla; ii) modelos matemáticos baseados em aprendizagem de máquinas, tais como as Redes Neurais Artificiais; iii) interpoladores espaciais para o preenchimento de falhas (Inverso da Distância, Vizinho Natural, Krigagem). Por fim, foi verificada uma evolução das técnicas de interpolação e de preenchimento de falhas nas últimas décadas, em decorrência da evolução da capacidade computacional e tecnológica.
\end{abstract}

Palavras-chave: precipitação, regressão, interpolação espacial, geoprocessamento.

\section{Gap Filling and Pluviometrics Spacialization Data: Challenges and perspectives}

\begin{abstract}
Precipitation is one of the most important climatic variables for urban and rural planning, to monitor extreme events that may have an impact on society and to assist in urban drainage projects, in order to reduce the risks of floods, or even engineering works, such as dams dimensioning. However, failures in extensive series hamper these studies, and it is necessary to use models to fill them. The present study aims to review the methods of filling in gaps and spatial interpolation of precipitation data. The review of the methods was carried out from the research and reading of bibliographic materials, in order to conceptualize the approaches, identify the advantages and disadvantages of each method and present how recent studies, national and international, have innovated when comparing the performance in different areas of study. Based on this review, the main methods for filling gaps are as follows: i) weighting from Simple or Multiple Linear Regression; ii) mathematical models based on machine learning, such as Artificial Neural Networks; iii) spatial interpolators for filling gaps (Distance Inverse, Natural Neighbor, Krigagem). Finally, there was an evolution in the interpolation and fault filling techniques in the last decades, due to the evolution of computational and technological capacity.
\end{abstract}

Keywords: precipitation, regression, spatial interpolation, geoprocessing.

Autor de correspondência: João Paulo Brubacher, jp.brubacher@hotmail.com. 


\section{Introdução}

O debate sobre mudanças climáticas globais coloca a variável precipitação no centro da discussão, sendo um parâmetro-chave no estudo do clima. Por se tratar de um importante componente do ciclo hidrológico, os processos resultantes da movimentação e armazenamento de água estão relacionados a diversos setores da sociedade, como abastecimento de água e irrigação, de forma que alterações no regime pluviométrico afetam o ambiente e a população como um todo (Mekis et al., 2018).

Conhecer o regime pluviométrico de uma bacia hidrográfica é determinante em projetos relacionados ao uso da água e de planejamento urbano (Henrichs et al., 2018), tanto para mitigar desastres relacionados a eventos extremos de precipitação, como inundações, enxurradas, alagamentos e movimentos de massa; quanto as dificuldades provocadas pela falta de chuvas, como as estiagens e as secas (Oliveira et al., 2005; Trenberth, 2011; Santos, 2015; Raghavendra et al., 2019; Zhao et al., 2019).

O monitoramento da precipitação e a organização de um banco de dados históricos ajudam a compreender a complexidade desses fenômenos, tanto para verificação de médias históricas quanto para espacialização e modelagem de eventos futuros (Zarekarizi et al., 2018). Estudos com viés ambiental de previsão do tempo, de modelagem e de variabilidade climática, por exemplo, principalmente no que se refere a análises de longo prazo, como simulação de inundações e dimensionamento de barragens, necessitam de séries temporais confiáveis de precipitação e vazão (Mateus, 2006; Li et al., 2010; Paz, 2010).

No Brasil, as redes de monitoramento são operadas pela Agência Nacional de Águas - ANA, que desenvolve e opera sistemas de alertas contra cheias em áreas críticas, além de produzir estudos em áreas específicas. No entanto, as estações pluviométricas existentes, não só no Brasil, mas no mundo (Villazón e Willems; 2010), podem apresentar lacunas nas séries de dados, especialmente no que se refere às séries mais longas.

O preenchimento de séries de precipitação costuma ser incômodo porque restrições físicas, como terrenos complexos e baixa densidade de estações meteorológicas, limitam o seu desempenho (Kim e Ryu, 2016). Falhas pluviométricas e hidrológicas podem ocorrer por erro humano, por falha nos aparelhos, no processamento ou por perda de dados. Para trabalhar com séries contínuas tornase necessário que essas falhas sejam preenchidas (Oliveira et al., 2010). Em simulações ou previsão hidrológicas, dificultam o ajuste de distribuições estatísticas aos dados históricos, reduz o desempenho de modelos hidrológicos ou até mesmo inviabiliza suas aplicações. Dessa forma, há a necessidade de preenchimento de falhas e verificar a consistência dos dados após o preenchimento (Bárdossy e Pegram, 2014; Depiné et al., 2014).
Existem diversos métodos para o preenchimento de lacunas em dados de precipitação. Boa parte deles se baseia na proposta de interpolação espacial, frequentemente aplicada com auxílio de ferramentas de geoprocessamento em softwares que manipulam dados georreferenciados, como os Sistemas de Informações Geográficas (SIG).

A integração entre modelos hidrológicos e SIG se apresenta como uma forma viável de descrever os processos hidrológicos em bacias hidrográficas (Baumgartner e Apfl, 1996; Collischonn et al., 2007, Melo et al., 2008). No entanto, limitações na manipulação de dados hidrológicos ocorrem devido à quantidade de dados relacionados com a variabilidade espacial e temporal das características que descrevem a heterogeneidade do seu comportamento, quando essa variabilidade implica em limitações na aplicação dos modelos (Machado, 2002).

Guimarães et al. (2017) utilizaram o software ArcGIS 10.2 e dados do Atlas Pluviométrico do Brasil, publicado pelo Serviço Geológico do Brasil, cuja série histórica é de 1977 a 2006, ou seja, 30 anos de dados, com o objetivo de realizar a espacialização pluviométrica na parte brasileira da bacia do rio Uruguai. Marcuzzo (2019) realizou o mesmo tipo de estudo para a região metropolitana de Teresina/PI, utilizando ainda o interpolador Topo to Raster. Ambos estudos demonstram a importância de conhecer o comportamento das chuvas de uma região, visando um contexto de sistema de alerta de eventos extremos.

Em linhas gerais, o monitoramento da precipitação é realizado a partir de pluviômetros e estações meteorológicas, com coleta pontual da precipitação. Neste caso, são aplicados métodos de interpolação para espacializar as chuvas (Cecílio e Pruski, 2003; Carvalho e Assad, 2005). O mapeamento da precipitação pluvial e de outras variáveis ambientais é de fundamental importância na pesquisa científica em recursos hídricos e hidrologia (Silva, 2011; Ly et al., 2013), agricultura e florestas (Viola et al., 2010; Fibbi et al., 2016), climatologia e meteorologia (Yang et al., 2015; Kim e Ryu, 2016; Gundogdu, 2017; Zhou, 2019).

Nesse contexto, o presente estudo tem como objetivo revisar os métodos de preenchimento de falhas e de interpolação espacial de dados de precipitação, conceituar as abordagens, identificar as vantagens e desvantagens de cada método e apresentar estudos nacionais e internacionais que têm feito inovações por meio de estudos comparativos com indicação de desempenho em diferentes áreas de estudo.

\section{A Concepção dos Métodos de Preenchimento de Falhas e Interpolação Espacial}

As redes hidrometeorológicas de monitoramento no mundo tiveram diferentes períodos de funcionamento, algumas funcionam há mais de um século, outras funcio- 
naram por poucos anos ou em períodos escalonados. No Brasil, poucas estações possuem mais de cem anos de dados disponíveis (Bier e Ferraz, 2017). No entanto, tanto as redes mais antigas quanto as mais novas e modernas, podem apresentar lacunas nas séries.

$\mathrm{O}$ aumento da disponibilidade de dados, segundo Mekis et al. (2018), inclusive de estações manuais de longa duração, beneficiam os usuários. A restrita cobertura espacial e a qualidade dos dados são problemas a serem enfrentados. Dependendo da aplicação, séries de dados com falhas podem, ter seu uso descartado, devido à necessidade de confiabilidade. Caso isso não aconteça, a espacialização e a análise estatística relacionados à frequência e à distribuição de eventos extremos podem ter seus resultados prejudicados.

Uma importante restrição deve ser seguida para o preenchimento de falhas, que se refere à seleção de estações meteorológicas ou pluviométricas utilizadas. Segundo Zeilhofer et al. (2003), para preenchimento de falhas é necessário utilizar pares de pontos com máxima correlação. Leivas et al. (2006) recomendam a seleção de estações meteorológicas da mesma região ecoclimática e altitude semelhantes, caracterizando-a como hidrologicamente homogênea. Essa escolha se mostra coerente, pois aumenta a possibilidade de que os dados pluviométricos sejam semelhantes entre as estações, e maior a probabilidade de boa correlação em relação às lacunas existentes, determinante na escolha da técnica de interpolação.

A análise de eventos de precipitação engloba processos hidrológicos estocásticos, governados por leis de probabilidade, porém com componentes aleatórios que estão acima das regularidades eventualmente explicáveis (Naghettini e Pinto, 2007). Seguindo essa lógica, Junior e Vanzela (2016) avaliaram a influência do relevo na distribuição espacial das precipitações médias anuais e mensais de Caraguatatuba, SP, e concluíram que o relevo exerce influência significativa sobre a distribuição espacial das precipitações. Segundo Groisman e Legates (1993) e Viola et al. (2010) a altitude é um parâmetro relevante como variável secundária no processo de interpolação espacial, devendo ser incorporada à análise para obtenção de mapeamentos mais precisos e realistas da precipitação.

Como os padrões espaços-temporais das chuvas são complexos, não lineares e altamente variáveis, a distribuição espacial das estações pluviométricas e a distância entre elas tem grande influência no preenchimento de falhas e interpolação de dados, visando gerar superfícies homogêneas de precipitação (Depiné et al., 2014).

Observa-se na literatura científica uma série de métodos utilizados para o preenchimento de falhas como, por exemplo: i) ponderação a partir de Regressão Linear Simples ou Múltipla; ii) modelos matemáticos baseados em aprendizagem de máquinas, tais como as Redes Neurais Artificiais; iii) interpoladores espaciais para o preenchi- mento de falhas (Inverso da Distância, Vizinho Natural, Krigagem).

Na Regressão Linear Simples (RLS) ou Regressão Linear Múltipla (RLM), a precipitação no posto com falhas é correlacionada estatisticamente com a precipitação em um posto vizinho com dados, no caso da regressão simples, ou vários postos vizinhos, no caso da regressão múltipla. Segundo Tucci (2002) e Bertoni e Tucci (2007) no método RLS, as estimativas dos parâmetros são obtidas graficamente ou por meio dos mínimos quadrados para calibração dos valores de forma iterativa.

$\mathrm{Na}$ regressão múltipla, as informações pluviométricas do posto $Y$ são correlacionadas com as observações correspondentes de vários postos vizinhos, por meio de uma equação linear (Eq. (1)) ou por outros tipos de relação, como a potencial (Eq. (2)). A segunda expressão pode ser linearizada por meio dos logaritmos dos valores das variáveis envolvidas.

$$
\begin{gathered}
Y=\beta_{o}+\beta_{1} \cdot X_{1} \beta_{2} \cdot X_{2}+\beta_{i} \cdot X_{i}+\varepsilon \\
Y c=a_{1} \cdot x 1_{i}^{a_{2}} \cdot x 2_{i}^{a_{3}} \cdot x 3_{i}^{a_{4}} \ldots x n_{i}^{a_{n}}
\end{gathered}
$$

em que $Y$ é a variável dependente, nesse caso, a precipitação estimada; $X_{1}, X_{2}, \ldots X_{i}$, são os as variáves independentes, nesse caso os postos considerados; $\beta_{o}, \beta_{1}, \beta_{2}, \ldots$ $\beta_{2 i}$, são os coeficientes da regressão; e $\varepsilon$ indica o erro residual.

Apesar da aparente limitação, uma das vantagens do método é permitir interpretar o fenômeno sem grande esforço computacional e simples interpretação. As RLM são muito utilizadas, e produzem bons resultados sempre que a variável a ser estimada depende fortemente de dois ou mais atributos ou variáveis preditivas (Fonseca et al., 2012).

Um segundo conjunto de métodos, relacionado à aprendizagem de máquina e uso de inteligência artificial, é mais complexo e demanda um esforço computacional maior para realizar a regressão entre as variáveis de entrada e a saída. Os avanços recentes na computação e no geoprocessamento, são utilizados para estimar variáveis numéricas da natureza, tais como a precipitação. Destacam-se as Redes Neurais Artificiais (RNA) e a Máquina de Vetores de Suporte (MVS).

A RNA é um modelo computacional inspirado no comportamento dos neurônios biológicos e consiste em um grande número de processamentos simples com muitas interconexões (Gupta, 2013). São algoritmos que utilizam técnicas de inteligência artificial, e a aprendizagem é de forma iterativa, sem a interferência direta do usuário ou pesquisador. As RNA multicamadas contêm um conjunto de neurônios de entrada, uma camada de saída e uma ou mais camadas intermediárias, também chamadas camadas ocultas (Guarnieri, 2006). 
Os dados são recebidos por meio dos neurônios na primeira camada (os atributos ou variáveis de entrada), produzem sinais de saída e estimulam os neurônios na camada intermediária, até a camada de saída (a variável a ser modelada). A Fig. 1 mostra a arquitetura de uma RNA com três entradas, duas camadas intermediárias com quatro neurônios cada e uma camada de saída com um neurônio, produzindo uma única informação de saída.

Uma RNA é composta por um conjunto de elementos computacionais, denominados neurônios artificiais, que relacionam os valores de saída e de entrada por uma equação generic (Eq. (3)):

$$
y^{i j}=f\left(\sum_{i^{j}}^{n} y^{i(j-1)} w_{i^{j}}^{i j}+b^{i j}\right)
$$

em que $y^{i j}$ é o valor de saída do neurônio $i$ da camada $j ; n$ é o número de neurônios da camada anterior; $y i^{\prime}(j-1)$ é o valor de saída do neurônio $i^{\prime}$ da camada anterior; $w_{i^{\prime}}^{i j} y i^{\prime}(j-$ 1) é o valor do peso sináptico do neurônio $i$ da camada $j$, ativado pelo neurônio $i^{\prime}$ da camada anterior; $b^{i j}$ é o valor de compensação do neurônio $i$ da camada $j ; f$ é a função de ativação do neurônio $i$, podendo ser linear, sigmoidal ou outra.

Um dos algoritmos mais utilizados para modelar dados numéricos usando RNA é o método retropropagativo com múltiplas camadas (Rumelhart et al., 1986), usando a Regra Delta (Widrow e Hoff, 1960) para atualização dos pesos sinápticos da rede. Os valores dos atributos de entrada costumam ser escalonados a partir de transformações lineares, já que a diferença de unidades de medidas entre as entradas pode influenciar no desempenho da rede.
Nas RNA, se utiliza uma série de validação cruzada paralela à série de treinamento e um número limitado de ciclos de aprendizagem, evitando o superajustamento do modelo e garantindo uma boa capacidade de generalização da rede para a estimativa dos valores de precipitação. É comum testar conjuntos de atributos de entrada e número de neurônios na camada intermediária da rede, para adequar a arquitetura de RNA para o problema modelado. Uma vez que a inicialização dos pesos é aleatória, um conjunto de iterações também é necessário para cada configuração do modelo, pois não há garantia de que já na primeira tentativa se atinja um ótimo ajuste dos pesos sinápticos da rede (Oliveira et al., 2015).

As RNA aprendem de modo iterativo e generalizam, ou seja, aprendem de forma autônoma, extraem informações de amostras dos valores de entrada e suas saídas e generalizam através da sua capacidade de responder a situações não previstas durante a aprendizagem (Dornelles et al., 2013). Uma das principais vantagens das RNA é a sua capacidade de solucionar problemas, por meio da aprendizagem a partir de exemplos, e generalizar a informação fornecida (Zanata, 2005), e são potencialmente capazes de tratar relações não-lineares entre as variáveis independentes (Matsumoto, 2008).

De acordo com Sárközy (1999) podem ser usadas como ferramentas de interpolação. Sua capacidade de aprendizado para diferentes parâmetros de entrada a torna capaz de resolver problemas complexos, incluindo a estimativa de precipitação a partir dos valores observados em postos vizinhos. Para previsão espacial de chuvas intensas (French et al., 1992), as RNA são capazes de modelar relações não-lineares sem a necessidade de assumir previamente uma distribuição básica para os dados, além da possibilidade de trabalhar com uma grande quantidade de dados (Valença, 1999). É potencialmente útil em situações

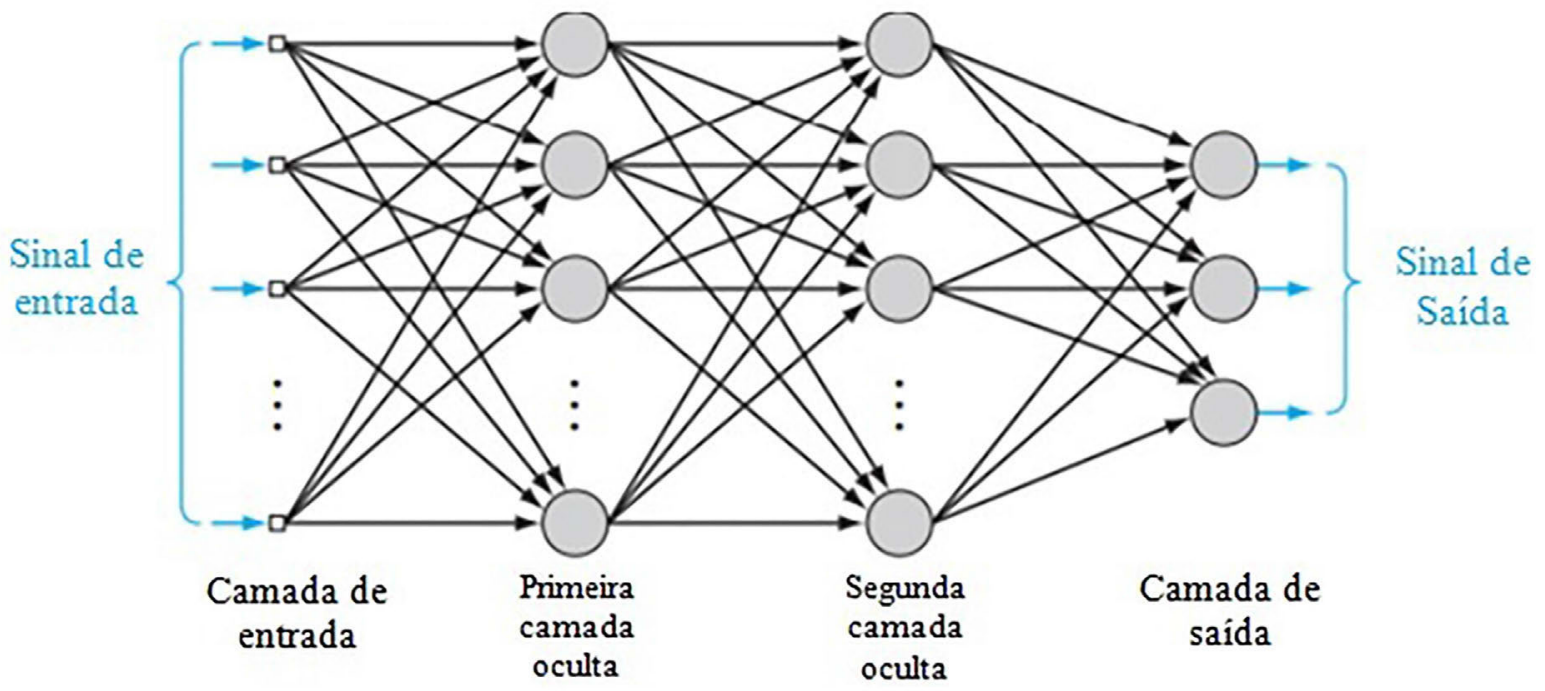

Figura 1 - Exemplo da estrutura de funcionamento de uma rede neural artificial. Fonte: Adaptado de Haykin, 2008. 
nas quais as relações dos processos físicos ainda não são completamente compreendidas (Sousa e Souza, 2010).

Outro método que se destaca é a Máquina de Vetores de Suporte (MVS), que representa um conjunto de métodos de aprendizagem supervisionados para classificação e regressão. O classificador MVS mapeia os vetores de características das amostras (pixels, por exemplo), como entrada para o algoritmo em um espaço de maior dimensão, onde se supõe que elas sejam separáveis linearmente (Freitas et al., 2010). Segundo Schölkopf e Smola (2002) tem uma fundamentação mais sólida do que as RNA, sendo capazes de substituí-las com desempenho semelhante. Para Weigend et al. (1995), com sua extensão para o tratamento de problemas de regressão, a MVS mostra-se altamente competitiva, com destaque para as aplicações envolvendo predição de séries temporais.

A aplicação de MVS como técnica de regressão se dá pela introdução de uma função de perda (Schölkopf e Smola, 2002) na qual, segundo Lima (2004), ocorre uma reversão de propósito quando comparado ao tratamento adotado junto a problemas de classificação binária, com o objetivo de maximizar a capacidade de generalização. As MVS possuem diferentes núcleos que caracterizam o seu reconhecimento de padrões, entre os quais: Linear, Polinomial, Gaussiano e Sigmoidal.

Uma das principais vantagens das MVS é a elevada capacidade de generalização, ou seja, se trata de uma medida da eficiência na previsão de dados que não pertençam ao conjunto utilizado para o treinamento, evitando-se o superajustamento, situação na qual se obtêm baixos erros no conjunto de treinamento e erros elevados no conjunto de previsão (Ferrão et al., 2007).

$\mathrm{O}$ terceiro grupo de métodos utilizados no preenchimento de dados de precipitação se refere aos interpoladores espaciais. Embora nem sempre apresentem os melhores índices de desempenho e acurácia, sua vantagem para estimar e preencher falhas históricas se deve ao contexto espacial, isto é, utiliza a localização para ponderar o peso de cada estação na estimativa (Castro et al., 2010; Wagner et al., 2012).

A interpolação espacial é um procedimento matemático e/ou geoestatístico de ajuste de uma função para estimar valores de uma variável em um local a partir de pontos amostrais, derivando uma superfície contínua que representa a grandeza do evento analisado, denominada como modelo digital ou modelo numérico (Landim, 2000). Se diferencia dos anteriores por sua capacidade de ponderar pontos amostrais pela distância ou pela localização e tem a grande vantagem de facilitar a distribuição espacial de dados pontuais, estimando os dados recorrentes entre as amostras (Giacomin et al., 2014).

Em ambiente SIG, técnicas de geoprocessamento são aplicadas para espacializar as variáveis de entrada do modelo (Viola et al., 2009). Segundo Deroo e Jetten (1999) razão do uso do SIG é que o processo varia espa- cialmente e, assim, células de informação devem ser usadas para que a variação espacial seja considerada. Essa técnica facilita verificar a forma de distribuição espaço e no tempo das variáveis obervadas nas séries históricas (SILVA et al., 2007).

$\mathrm{Na}$ interpolação são usadas funções matemáticas, produzidas por modelos determinísticos, que podem não representar os fenômenos físicos através de conjunto de fatores que estão na sua formação. Seu objetivo é interpolar espacialmente os valores observados (Burrough, 1986; Soares, 2000). Alguns interpoladores são utilizados como técnicas para espacializar dados de precipitação, o que permite reconhecer o fenômeno de precipitação analisado, seja em períodos mais chuvosos ou mais secos, mesmo em áreas que não possuem estações pluviométricas ou para o preenchimento de falhas em locais monitorados.

Entre as técnicas de interpolação espacial, pode-se destacar: Inverso da Potência da Distância (IPD); Vizinho Natural (VN); Spline (SPL); Krigagem (KRG). Esses métodos permitem adotar critérios de busca de pontos amostrais vizinhos ao local onde se deseja estimar a precipitação. Os mais comuns são: i) raio de alcance da amostragem; ii) número máximo de pontos amostrais; iii) busca de amostras com limite por quadrante ou octante (Valente, 1995).

O IPD é adotado em estudos do clima, para interpolar precipitação diária em bacias hidrográficas, ou parâmetros de equações de chuvas intensas para locais desprovidos de dados pluviométricos, utilizando estações meteorológicas adjacentes (Assad e Evangelista, 1994). De acordo com Lam (2013) é um ponderador versátil, fácil de programar e bastante preciso. Sua formulação (Eq. (4)) estabelece que o peso de uma estação ou ponto amostral é inversamente proporcional a sua distância (elevada a uma determinada potência) do local onde se deseja estimar o valor. O IPD é um interpolador determinístico univariado de médias ponderadas (Mello et al., 2009).

$$
x p=\frac{\sum_{i=1}^{n}\left(\frac{1}{d_{i}^{p}} \cdot x i\right)}{\sum_{i=1}^{n}\left(\frac{1}{d_{i}^{p}}\right)}
$$

em que $x p$ é o atributo interpolado; $x_{i}$ é o valor do atributo do i-ésimo ponto de amostragem; $d_{i}$ é a distância euclidiana entre o i-ésimo ponto de vizinhança e o ponto amostrado; $n$ é o número de amostras; $p$ é a potência escolhida.

O IPD limita a interpolação ao intervalo dos valores utilizados, isto é, não gera uma resposta de saída fora do domínio de valores de entrada dos postos pluviométricos vizinhos. Os pesos são avaliados durante o processo de interpolação, tal que a influência de cada ponto é inversamente proporcional à distância do nó da grade de interpolação. É considerado um interpolador exato ou suavi- 
zante no ponto amostral (Mazzini e Schettini, 2009). Os resultados são melhores quando a amostragem é suficientemente densa em relação à variação local que se está interpolando. Se a amostragem for escassa ou desigual, os resultados podem não representar suficientemente a superfície desejada (Dirks et al., 1998; Mello et al., 2003).

A sua principal vantagem é a simplicidade, além de levar a resultados razoáveis para uma ampla variedade de dados (Caruso e Quarta, 1998). Por outro lado, o método é muito sensível à função de ponderação, ou seja, o método pode ser afetado pela distribuição desigual dos dados.

O método do Vizinho Natural (VN) utiliza a triangulação de Delaunay e o diagrama de Voronoi para descobrir a vizinhança mais apropriada para obter o valor de precipitação em um dado ponto, a partir de um conjunto amostral (Fig. 2A). É adequado tanto para malhas regulares como irregulares (Watson, 1999). O VN não extrapola valores, resolvendo a interpolação somente para $\mathrm{o}$ interior do domínio dos dados, assim como o IPD.

Os polígonos de Voronoi são construídos a partir da triangulação de Delaunay (Fig. 2B). Uma propriedade da triangulação é de que uma circunferência qualquer definida pelos três vértices de um triângulo não pode conter qualquer outro ponto amostral no seu interior. Os polígonos são construídos, considerando como vértices o centro das circunferências que envolvem os triângulos, formando áreas irregulares (Fig. 2C). A técnica de Voronoi é aplicada novamente, porém considerando o local de interesse na triangulação, para identificar a área de influência do local de interpolação (Fig. 2D). Por fim, a área de intersecção entre os polígonos de Voronoi (um polígono para cada estação pluviométrica) e a área de influência do ponto a ter o valor interpolado revela o peso de cada estação na estimativa da precipitação (Fig. 2E) (Sibson, 1981; Lança, 2004; Mazzini e Schettini, 2009; Smith, 2009).

A principal diferença entre VN e IPD, é que o VN leva em consideração não apenas a distância entre as estações pluviométricas e os nós da grade de interpolação, mas também a direção e a geometria gerada pela malha de estações amostrais (Sibson, 1981). No método VN, apenas a estação pluviométrica mais próxima em cada direção é ponderada no processo de interpolação.

O Spline (SPL), também considerado como mínima curvatura, utiliza um polinômio para gerar uma superfície que minimize a curvatura da mesma, resultando em uma superfície suavizada através dos pontos amostrados reproduzindo os valores de cada variável (Andriotti, 2005). O autor destaca que isto não ocorre sempre, e não pode ser considerado um interpolador exato, pois o polinômio pode gerar valores fora do domínio de amostragem.

O SPL se distingue de outros métodos de interpolações polinomiais, por não utilizar apenas um polinômio de grande ordem para a interpolação do conjunto de dados. Divide a série em subconjuntos e utiliza polinômios de pequenas ordens para cada subconjunto (Mazzini e Schettini, 2009). Gera um novo grid de pontos e aplica
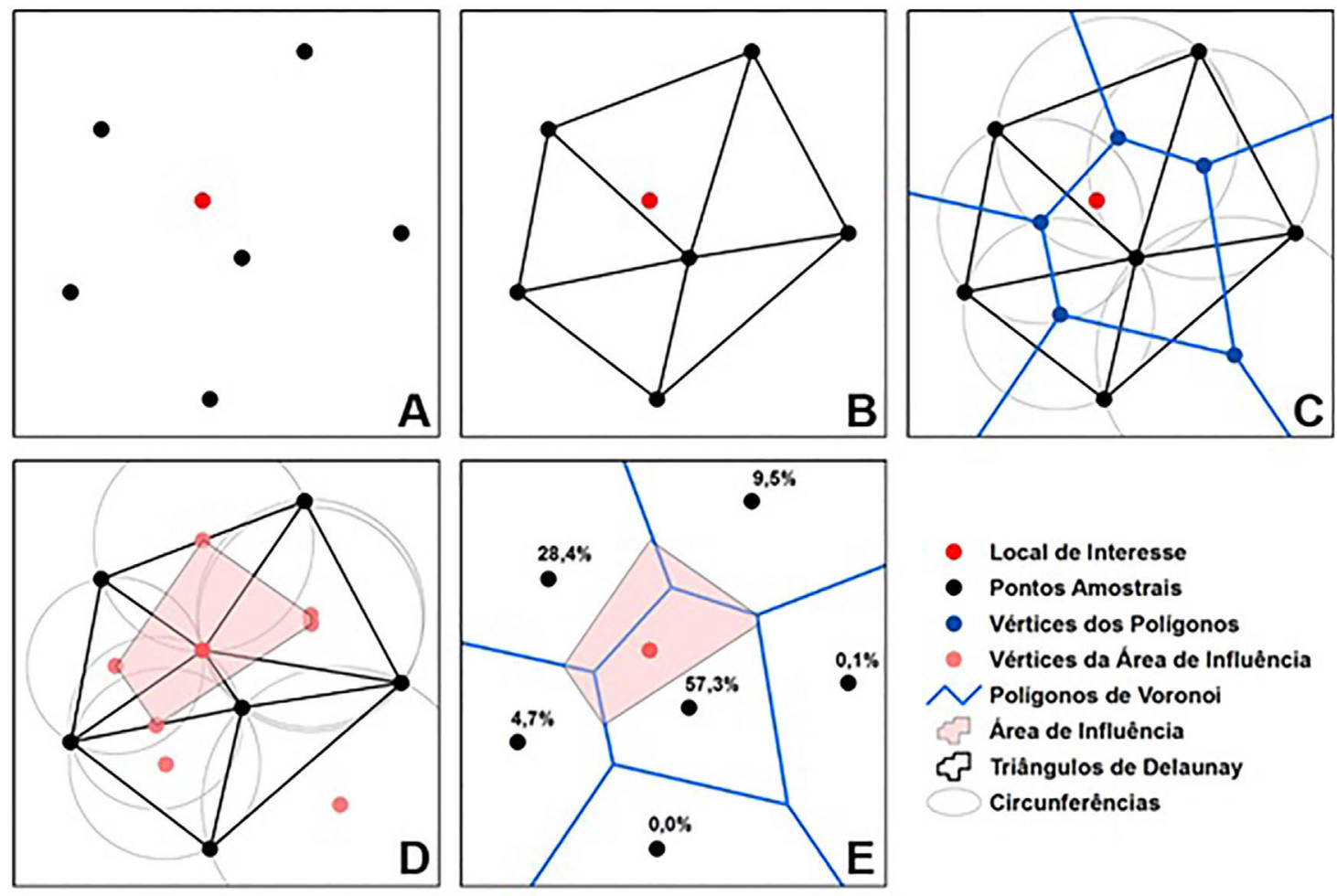

Figura 2 - Processo de interpolação pelo método do vizinho natural, baseado na triangulação de Delaunay e no diagrama de Voronoi. Fonte: próprio autor. 
sucessivamente o modelo de regressão por mínimos quadrados sobre a grade de modo interativo, de forma que a cada passagem consiga atingir um melhor nível de suavização (Medina, 2008).

A interpolação por Splines origina anomalias na superfície da interpolação, em função da aplicação de polinômios de ordens maiores, não condizentes com os valores amostrais e superfície esperada (Lancaster e Salkauskas, 1975, apud Lam, 1983). Para Souza et al. (2011) não é um modelo adequado para espacializar a pluviosidade, suaviza o resultado e não contempla mudanças bruscas do fenômeno, gera erros na malha e prejudica a qualidade da superfície de chuva modelada e do preenchimento de falhas históricas nos dados pluviométricos.

Segundo Marcuzzo et al. (2011), uma função Spline $\mathrm{S}(\mathrm{x})$ (Eq. (5)), deve preencher a condição de que $\mathrm{S}(\mathrm{x})$ para os pontos medidos deve ser igual a $\mathrm{z}(\mathrm{x})$ e ao mesmo tempo a seminorma de suavização I(S) (Eq. (6)), deve ser o menor possível.

$$
\begin{gathered}
S\left(x_{j}\right)=z\left(x_{j}\right) \\
I(S)=\min
\end{gathered}
$$

em que $z\left(x_{j}\right)$ são valores das variáveis nos pontos $x_{j}$ amostrados; e I $(S)$ é uma função que mede a suavização de $S$, chamada de seminorma de suavização. Um ponto $x$ é definido pelos valores $\left(x_{1}\right.$ e $\left.x_{2}\right)$ sendo $x_{1}$ a localização na coordenada $x$ cartesiana e $x_{2}$ a coordenada $y$ cartesiana.

No caso da Spline de Tensão, $\mathrm{T}(\mathrm{x})=\mathrm{a}_{1}$, as constantes $a_{1}$ e $\lambda j$ são determinadas resolvendo o sistema (Eq. (7) e Eq. (8)):

$$
\begin{gathered}
a_{1}+N 1 \sum_{j=1}^{N} y r\left(x_{1} x_{j}\right)=z_{1}, i=1, \ldots, N \\
\sum_{j=1}^{N} \lambda j=0
\end{gathered}
$$

em que $x_{i}$ e $x_{j}$ são os pontos amostrados; e $z_{1}$ é o valor de $z$ no local de $x_{i}$.

Krigagem (KRG) é o nome genérico, adaptado pela geoestatística para a família de algoritmos de regressão de mínimos quadrados generalizados (Goovaerts, 1997). Tem a capacidade de produzir melhores estimativas, porque está embasada em duas premissas: não-tendenciosidade do estimador e variância mínima das estimativas (Thompson, 1992). A KRG é considerada, segundo Mello et al. (2003) e Remacre et al. (2008), um dos mais eficientes em interpolações espaciais. Estima a variável interpolada na posição $\mathrm{p}\left(X_{p}\right)$, a partir do estabelecimento do peso de Krigagem $(\lambda)$, de cada uma das $n$ observações vizinhas $\left(X_{i}\right)$, de acordo com sequência de cálculos (Eq. (9) e Eq. (10)) (Thompson, 1992):

$$
[A]^{-1} \cdot[b]=[\lambda]
$$

em que $[A]^{-1}$ é a matriz inversa de semivariância entre as localidades da vizinhança de um ponto, determinada pelo modelo de semivariograma com base nas distâncias euclidianas entre as localidades; é a matriz de semivariância entre as localidades vizinhas (com a variável estimada) e o ponto para o qual a variável será interpolada, também determinado pelo modelo de semivariograma, com base nas distâncias pelo entre as localidades vizinhas e o ponto a ser interpolado; $[\lambda]$ é a matriz de pesos da Krigagem.

$$
X_{p}=\sum_{i=1}^{n} \lambda_{i} \cdot X_{i}
$$

em que $X_{p}$ é a variável interpolada; $\lambda_{i}$ é o peso da i-ésima localidade vizinha; $X_{i}$ é o valor da variável para a i-ésima localidade; $n$ é o número de localidades vizinhas empregadas para interpolação do ponto.

A extensão multivariada da Krigagem, conhecida como Cokrigagem, é um procedimento geoestatístico, no qual diversas variáveis regionalizadas podem ser estimadas em conjunto, com base na correlação espacial cruzada entre a variável primária e a variável secundária (Isaaks e Srivastava, 1989). A grande diferença em relação à Krigagem ordinária está na modelagem da estrutura espacial do fenômeno por um modelo multivariado (variograma cruzado ou modelo multivariado de covariância) (Lam, 1983).

O semivariograma expressa o grau de dependência espacial entre amostras, dentro de um campo experimental, e estima os parâmetros com os quais os valores não amostrados são estimados por meio da Krigagem. Permite a construção de mapas de isolinhas ou tridimensionais para exame e interpretação da variabilidade espacial (Carvalho e Queiroz, 2002).

Utilizando-se Cokrigagem Ordinária, segundo Vieira (2000) e Viola et al. (2010), para se estimar um valor $Z_{o c}^{*}$ em qualquer local $x_{0}$, o valor estimado resulta de uma relação linear de $z_{1}$ e $z_{2}$ (Eq. (11) e Eq. (12)):

$$
z_{o c}^{*}\left(x_{0}\right)=\sum_{i=1}^{N_{1}} \lambda_{1 i} z_{1}\left(x_{1 i}\right)+\sum_{j=1}^{N_{2}} \lambda_{2 j} z_{2}\left(x_{2 j}\right)
$$

em que $N_{1}$ e $N_{2}$ são os números de vizinhos $Z_{1}$ e $Z_{2}$ respectivamente, e $\lambda_{1}$ e $\lambda_{2}$ são os pesos associados a cada valor de $Z_{1}$ e $Z_{2}$. Ao se tomar $Z_{1}\left(x_{1 i}\right)$ e $Z_{2}\left(x_{2 j}\right)$ como sendo a realização das funções aleatórias $Z_{1}\left(x_{1 i}\right)$ e $Z_{2}\left(x_{2 j}\right)$, respectivamente, e ao se assumir estacionaridade de ordem 2, o estimador pode ser reescrito como:

$$
Z_{o c}^{*}\left(x_{0}\right)=\sum_{i=1}^{N_{1}} \lambda_{1 i} Z_{1}\left(x_{1 i}\right)+\sum_{j=1}^{N_{2}} \lambda_{2 j} Z_{2}\left(x_{2 j}\right)
$$

Esta equação expressa a estimativa da variável $Z_{o c}^{*}$ deve ser uma combinação linear $Z_{1}$ e $Z_{2}$ : com os pesos $\lambda_{1}$ e $\lambda_{2}$ distribuídos de acordo com a dependência espacial de cada 
uma das variáveis entre si e com a correlação cruzada entre elas.

O Quadro 1 resume os principais métodos de preenchimento de falhas e interpolação utilizados para análise da precipitação.

\section{Estudos Comparativos de Métodos de Preenchimento de Falhas e Interpolção Espacial da Precpitação}

Castro et al. (2010) avaliaram o desempenho dos métodos de interpolação IPD e KRG para especializar as seguintes variáveis meteorológicas: precipitação, deficiência hídrica, excedente hídrico, evapotranspiração potencial, evapotranspiração real e disponibilidade hídrica. O método KRG foi mais eficiente para especializar os parâmetros climáticos, com base no menor valor da Raiz do Erro Médio Quadrático (REMQ) e outros parâmetros que auxiliaram na escolha do melhor modelo.

Gardiman Jr. et al. (2012) compararam o desempenho de cinco métodos de interpolação: Inverso da Quadrado da Distância (IPD), Krigagem esférica (KRG), Vizinho Natural (VN), Spline regularizada e Topo to Raster, para analisar dados pluviométricos numa bacia hidrográfica, em um período de 30 anos. Nesse caso, KRG obteve o melhor desempenho nas métricas de Erro Quadrado Médio (EQM), Percentual de Eficiência (EF\%), Erro Médio Absoluto (EMA), Coeficiente de Determinação $\left(\mathrm{R}^{2}\right)$ e Estimativa do Erro Padrão (EEP). A diferença entre os valores observados e estimados pelo método KRG foi menor, se comparado aos outros quatro métodos, representando melhor a distribuição espacial da precipitação pluvial média mensal para a bacia.
Em estudo comparativo entre métodos para espacialização de precipitação, Borges et al. (2016) aplicaram Regressão Múltipla, Cokrigagem, KRG, IPD e SPL, em dados de seis estações pluviométricas, e analisaram qual método foi mais realista ao estimar as precipitações sazonais e anuais. A diferença entre os métodos foi pequena e diminui conforme a rede de observação aumenta. De modo geral, os resultados foram semelhantes onde as redes de observações são densas, com maior confiabilidade dos métodos IPD, KRG e Regressão Múltipla.

Xu et al. (2015) testaram métodos de interpolação para produzir superfícies de chuva, com base na observação da precipitação diária em 43 estações meteorológicas com KRG, Cokrigagem e IPD. A Krigagem e Cokrigagem registraram menor erro médio que o IPD. A Cokrigagem apresentou os melhores resultados, uma vez que o método considerou as características topográficas do terreno. Em áreas mais complexas, com alta elevação e declividade, a Cokrigagem melhorou a precisão da interpolação espacial das chuvas.

Os métodos IPD e variações de KRG: krigagem ordinária (OK), a krigagem simples (SK), Krigagem universal (UK), Krigagem do indicador (IK), a Krigagem da probabilidade (PK), a Krigagem disjuntiva (DK) e a Krigagem bayesiana empírica (EBK), fora avaliados por Javari (2017) utilizando precipitação mensal para um período de 40 anos, em 140 estações. Os menores valores para a Raiz do Erro Médio Quadrático (REMQ) foram encontrados para IPD $(0,497)$, OK $(0,37)$, UK $(0,398)$ e EBK $(0,189)$, fazendo com que esses métodos fossem considerados os mais adequados.

Três técnicas de interpolação espacial (KRG, IPD e SPL) foram avaliadas por Das et al. (2017), para identifi-

Quadro 1 - Principais métodos para preenchimento de falhas e interpolação da precipitação.

\begin{tabular}{|c|c|c|c|c|}
\hline & Métodos & Referências & Vantagens & Desvantagens \\
\hline $\begin{array}{l}\text { Funções gerais de re- } \\
\text { gressão entre variá- } \\
\text { veis }\end{array}$ & $\begin{array}{l}\text { Regressão Linear Simples } \\
\text { (RLS), Regressão Linear } \\
\text { Múltipla (RLM) e demais } \\
\text { ajustes de curvas ou super- } \\
\text { fícies por meio de funções } \\
\text { matemáticas. }\end{array}$ & $\begin{array}{l}\text { Wilks, 2006; Fernandez, } \\
\text { 2007; Tucci, 2009; Villazón } \\
\text { e Willems, 2010; Bier e Fer- } \\
\text { raz, 2017; Souza et al., } \\
\text { 2017; Malfatti et al., 2018. }\end{array}$ & $\begin{array}{c}\text { Modelos de simples utilização } \\
\text { e interpretação; não necessitam } \\
\text { de grande esforço computacio- } \\
\text { nal; extensas bibliotecas de } \\
\text { funções disponíveis em soft- } \\
\text { wares para uso, fácil ajuste e } \\
\text { validação. }\end{array}$ & $\begin{array}{l}\text { Baixa capacidade de genera- } \\
\text { lização dos dados, muitas vezes, } \\
\text { desconsiderando relações não- } \\
\text { lineares entre as variáveis. }\end{array}$ \\
\hline $\begin{array}{l}\text { Inteligência artificial } \\
\text { e aprendizagem de } \\
\text { máquinas }\end{array}$ & $\begin{array}{l}\text { Redes Neurais Artificiais } \\
\text { (RNA), Máquina de Vetores } \\
\text { de Suporte (MVS) e demais } \\
\text { técnicas e algoritmos de } \\
\text { aprendizagem autômata. }\end{array}$ & $\begin{array}{l}\text { Boser, 1992; Assad e Evan- } \\
\text { gelista, 1994; Pinto, 1999; } \\
\text { Umehara et al. 2005; Gupta, } \\
\text { 2013; Mekanik et al., 2013; } \\
\text { Cerri e Carvalho, 2017; } \\
\text { Sulaiman e Wahab, 2017. }\end{array}$ & $\begin{array}{l}\text { Grande capacidade de aprendi- } \\
\text { zado, adaptabilidade e de gene- } \\
\text { ralização, principalmente em } \\
\text { situações complexas; modelos } \\
\text { costumam apresentar melhor } \\
\text { desempenho e acurácia. }\end{array}$ & $\begin{array}{l}\text { Requer maior esforço computa- } \\
\text { cional; grande volume de dados } \\
\text { gerados; maior dificuldade de } \\
\text { interpretação dos resultados. }\end{array}$ \\
\hline $\begin{array}{l}\text { Interpolação espacial } \\
\text { ponderada pela loca- } \\
\text { lização e/ou outras } \\
\text { variáveis espaciais }\end{array}$ & $\begin{array}{l}\text { Inverso da Potência da Dis- } \\
\text { tância (IPD), Vizinho Natural } \\
\text { (VN), Splines (SPL), Kriga- } \\
\text { gem (KRG) e demais métodos } \\
\text { geoestatísticos para estimativa } \\
\text { de valores no espaço. }\end{array}$ & $\begin{array}{l}\text { Sibson, 1981; Isaaks e Sri- } \\
\text { vastava, 1989; Phillips } \\
\text { et al., 1992; Thompson, } \\
\text { 1992; Gong et al., 2014; } \\
\text { Giacomin et al., 2014; Ali } \\
\text { et al., 2017; Javari, 2017; } \\
\text { Batista et al., 2018. }\end{array}$ & $\begin{array}{l}\text { Os pesos são determinados } \\
\text { considerando contexto espacial } \\
\text { e não de forma indireta como } \\
\text { nas demais técnicas; costuma } \\
\text { ser mais eficiente para regiões } \\
\text { com alta densidade de amos- } \\
\text { tras; não necessitam de grande } \\
\text { esforço computacional. }\end{array}$ & $\begin{array}{l}\text { O desempenho desses modelos é } \\
\text { prejudicado pela distribuição } \\
\text { irregular de pontos amostrais; } \\
\text { alguns métodos não consideram } \\
\text { a correlação das variáveis, resul- } \\
\text { tando em erros maiores na esti- } \\
\text { mativa dos valores. }\end{array}$ \\
\hline
\end{tabular}


car a técnica mais eficiente, utilizando dados de precipitação no período entre 1901 e 1985 . Os erros das três interpolações foram analisados com base no desvio absoluto médio mínimo (MAD) e critério mínimo de desvio médio quadrático (MSD), indicando o IPD com os melhores índices de desempenho.

Coulibaly e Becker (2009) avaliou o desempenho de quatro métodos de interpolação espacial (IPD, Krigagem, Krigagem ordinário, Krigagem Universal e Cokrigagem) usando a precipitação coletada de 545 estações A KRG demonstrou melhor desempenho em comparação com os outros métodos.

Para o preenchimento de falhas em séries de precipitação, Wanderley et al. (2012) utilizaram Krigagem, em dados de 63 estações pluviométricas, entre os anos de 1965 a 1980. A geoestatística com a análise variográfica mostrou que as características estruturais da precipitação estão correlacionadas e apresentam forte dependência espacial. A estimativa da precipitação apresentou resultados satisfatórios, para a distribuição espacial da precipitação, bem como para o preenchimento de falhas.

Ao testar RNA para o preenchimento de falhas, Depiné et al. (2014) utilizaram uma série de dados pluviométricos de nove estações. Foram experimentadas três alternativas: séries longas de treinamento e verificação, com aproximadamente 365 dias; séries curtas de treinamento com aproximadamente 12 a 30 dias, e várias séries também curtas de verificação, independentes da estação climática; séries curtas, porém com verificação do preenchimento somente em períodos próximos ao treinamento. Os melhores resultados foram obtidos coeficientes de Nash-Sutcliffe (NS) superiores a 0,9.

Correia et al. (2016) preencheram falhas de séries de precipitação utilizando RNA, aplicado a quatro estações pluviométricas. A RNA, no cálculo de preenchimento de falhas em dados mensais de pluviosidade foi eficaz com $7 \%$ de falha nos dados, apresentando valores de NSE e $\mathrm{R}^{2}$ superiores a 0,8 . A aplicação das mesmas redes em banco de dados com falhas de 15 e $30 \%$, não foi satisfatório.

Visando o preenchimento de falhas de precipitação, aplicados a séries de dados mensais para estações meteorológicas, Bier e Ferraz (2017) compararam seis métodos: Regressão Linear Múltipla (RLM), Ponderação Regional (PR), Inverso da Potência da Distância (IPD), Método da razão normal (MRN), Krigagem Universal (KRG), Média aritmética simples (MA). Os métodos foram aplicados e comparados com estações meteorológicas utilizadas como testes. Foi retirado o período de um ano de dados mensais da série original para validação dos resultados. Nenhum método se sobressaiu, apenas MA e MRN apresentaram pequena vantagem.

De acordo com a área de interesse e a distribuição dos dados, tanto no tempo quanto no espaço, um método pode se sobrepor a outro em relação a acurácia. Dessa forma, não existe um consenso entre os autores em relação a quais métodos se utilizar em cada situação. Esse é um dos fatos que explicam os estudos comparativos, muitas vezes com base em vários métodos, afim de se extrair os melhores resultados de preenchimento de falhas.

\section{Geoprocessamento e SIG na Espacialização da Precipitação}

A utilização de geoprocessamento e SIG para espacialização da precipitação estão bem consolidadas. De acordo com Câmara e Davis (2001), essa realidade era muito difícil de ocorrer na década de 1960, portanto, ainda é recente a sua utilização para obtenção e espacialização de variáveis hidrometeorológicas. A disponibilidade gratuita de diversos produtos de Sensoriamento Remoto e de softwares de Geoprocessamento tornou possível qualquer pessoa ou instituição produzir dados de qualidade a baixo custo (Crepani, 2004).

Os SIGs mais utilizados da atualidade, sejam de código aberto ou pagos, possuem ferramentas para interpolação de dados de precipitação, muitos dos quais citados nesse artigo, de modo que essas técnicas contribuem para qualificar os métodos utilizados visando tanto o preenchimento de dados quanto a interpolação espacial. $\mathrm{O}$ Quadro 2 apresenta alguns dos principais SIGs e os métodos de interpolação que podem ser utilizados.

Para Marcuzzo et al. (2011), a análise correta da distribuição espacial das precipitações é de suma importância para o planejamento dos recursos hídricos em bacias hidrográficas, além de suporte a estudos climatológicos e meteorológicos. As técnicas de espacialização facilitam entender os fenômenos de precipitação no espaço e no tempo, ou seja, levando em conta grandes ou pequenas bacias hidrográficas e diferentes períodos de análise. Podem dar suporte e permitir a relação entre a precipitação

Quadro 2 - Principais SIGs e disponibilidade de interpoladores

\begin{tabular}{ll}
\hline SIGs & Métodos de interpolação disponíveis \\
\hline ArcGIS & IDW, Krigagem, Spline, Spline com Barreiras, Vizinho Natural, Topo para Raster, RNA \\
QGIS & IDW, TIN, Spline, Vizinho Natural, Regressão Polinomial, Krigagem, Superfície de Tendência \\
SURFER & $\begin{array}{l}\text { IDW, TIN, Spline, Vizinho Natural, Regressão Polinomial, Krigagem, Regressão Polinomial, Triangulação Linear, Triangulação de Delaunay, } \\
\text { Polígonos de Voronoi }\end{array}$ \\
IDRISI & IDW, Krigagem, TIN, Vizinho Natural, Vizinho mais próximo \\
SPRING & TIN, Krigagem, Vizinho mais próximo
\end{tabular}


e fatores ambientais, assim como desastres desencadeados por eventos extremos de precipitação (Castro et al., 2010).

$\mathrm{Na}$ análise espacial, SIG ultrapassa a técnica analógica de armazenar informações geográficas em mapas, transferindo-as para um ambiente digital. Facilita a representação visual e a comparação de um conjunto de variantes, tais como sobreposição de camadas (Alves, 2011). Permitem integrar diferentes aspectos do ambiente, de forma rápida, principal motivo de sua utilização pelos pesquisadores para análise espacial de precipitação em bacias hidrográficas (Melo et al., 2008; Safre, 2015, Hu et al., 2016).

As técnicas de interpolação apresentam precisão e agilidade e permitem desenvolver práticas, como medidas mitigadoras em relação a suscetibilidade a desastres e a manutenção das atividades implantadas em uma localidade, onde o clima influencia diretamente na vida das população (Gardiman Junior et al., 2012).

Segundo Caruso e Quarta (1998), diferentes técnicas oferecem diferentes desempenhos, de acordo com as características dos dados de entrada. É necessário avaliar qual técnica melhor se adapta aos dados, bem como a quantidade de variáveis acrescentadas ao modelo. Com base nesses fatores, estabelece-se o método a ser aplicado que, no caso da espacialização da precipitação, vai ser diretamente relacionado com a qualidade dos dados de entrada.

Para Deroo e Jetten (1999), células de informação devem ser usadas para que a variação espacial seja levada em consideração no cálculo de precipitação. Técnicas de espacialização facilitam a verificação da forma como as variáveis nas séries históricas se distribuem no espaço e no tempo (Silva et al., 2011).

Para entender a variabilidade espacial e temporal das chuvas, Gimenez (2017) utilizou SIG no estudo de desastres naturais. Para o preenchimento de falhas, utilizou o método RNA e para interpolação dos dados de precipitação pluvial, a técnica de Krigagem. Dirks et al. (1998), Mello et al. (2003), Haylock et al. (2008), Santos et al. (2009), Marcuzzo et al. (2011), Brubacher et al. (2012) e Farias et al. (2017), utilizaram métodos de interpolação visando a espacialização da distribuição de dados de precipitação.

A importância do Geoprocessamento e do SIG na espacialização da precipitação se justifica tanto do ponto de vista econômico, social e ambiental. Além disso, cabe destacar que mesmo áreas remotas, com baixa densidade de estações pluviométricas, a precipitação pode ser estimada por meio de satélites e radares meteorológicos. Entres os satélites meteorológicos, destacam-se o GOES e o NOAA - AVHRR (EUA), o Meteosat (Europeu), o MTSAT (Japão), o FY-1 e FY-2 (China), o GOMS, o Meteor (Rússia) e o KALPANA (Índia) (MOREIRA et. el., 2017).

Entre os radares, o TRMM é o resultado de uma parceria entre a NASA e a JAXA (Agência Japonesa de
Exploração Aeroespacial), cuja grande vantagem deste produto em especial é sua alta resolução temporal, de 3 horas, e espacial, de $0.25^{\circ}$, na faixa entre $50^{\circ} \mathrm{S}$ e $50^{\circ} \mathrm{N}$ (Kummerow et al., 2000). O GPM (Global Precipitation Measurement), desenvolvido em conjunto pela NASA e JAXA, entre outros, visa monitorar globalmente, por meio de satélites, as precipitações na atmosfera, em alta resolução temporal de até 3 horas entre as observações (Hou et al., 2014), podendo chegar a $0,1^{\circ}$ e 1 hora (Huffman et al., 2014).

O princípio da estimativa de precipitação por meio do sensoriamento em bandas no visível é o fato de que o brilho da luz do sol refletida por nuvens pode ser uma indicação de sua espessura e consequentemente do volume de água em seu interior (Petty, 1995). Uma das vantagens da utilização das estimativas de precipitação por satélite é o número insignificante de falhas nas séries temporais, chegando a $0,1 \%$ da extensão total, dificilmente afetando toda a rede simultaneamente.

Serrão et al. (2016), demonstram a importância desse tipo de produto na região amazônica que, devido a sua grande extensão, tem dificultada a geração de informações para o monitoramento continuado dessa área. Nesse estudos, os autores realizaram uma análise estatística para comparar os dados gerados pelo algoritmo IMERG N3 do GPM em relação ao algoritmo 3B43 V7 do TRMM. Entre os principais resultados, foi constatado excelentes resultados em todos os meses estudados em relação a precipitação medida nas estações meteorológicas do INMET.

\section{Considerações Finais}

O preenchimento de falhas nas séries pluviométricas disponíveis para o território brasileiro é de fundamental importância principalmente no que se refere a análises de longo prazo, como simulação de inundações e dimensionamento de barragens, devido a necessidade de grande disponibilidade de dados de precipitação.

Embora ao longo dos anos tenham sido utilizados uma série de métodos para o preenchimento de falhas, trabalhos mais recentes, a nível nacional e mundial, tem se concentrado em métodos estatísticos e estocásticos. Nas Regressões Múltiplas, a simplicidade em utilizar e interpretar os dados se mostrou adequada. Por outro lado, as Redes Neurais Artificiais também se mostraram eficientes em áreas de maior complexidade no quesito quantidade e diversidade dos dados a serem corrigidos.

A evolução das técnicas de interpolação e preenchimento de falhas deu um salto nas últimas décadas, em decorrência da evolução da capacidade computacional e tecnológica. Dessa forma, diversos métodos foram potencializados devido a memória disponível, o que amplia o potencial de dados a ser utilizados.

O futuro das pesquisas na área poderia se debruçar em verificar melhorias nesses métodos, além de levar em 
conta o aspecto do relevo e possível influência no processo de preenchimento de dados, algo ainda pouco citado nas referências analisadas. Além disso, uma das dificuldades ao se trabalhar com esses dados diz respeito a necessidade de se realizar esses processamentos a cada novo estudo, de forma que o desenvolvimento de um modo organizado de divulgar dados preenchidos de estações, considerando amplas áreas de cobertura, ampliaria as possibilidades de estudos nessa área do conhecimento.

\section{Agradecimentos}

O presente trabalho foi realizado com apoio da Coordenação de Aperfeiçoamento de Pessoal de Nível Superior Brasil (CAPES) - Código de Financiamento 001; e da FAPERGS, processo 17/2551-0000894-4, Edital 01/2017.

\section{Referências}

Agência Nacional de Águas e Saneamento Básico. Disponível em: https://www.ana.gov.br/. Acesso em: 11 set. 2019.

ALI, S.; RAHMAN, A.; SALINAS, J.; GUNTER BLOSCHL, G. Applicability of Kriging to Regional Flood Estimation Problem in Eastern Australia. In: International Conference on Engineering Research and Practice, Dhaka, Bangladesh, p. 82-89, 2017.

ALVES, F.R. Avaliação de interpoladores para a espacialização de variáveis de precipitação na bacia hidrográfica do rio Ivaí. In: XV Simpósio Brasileiro de Sensoriamento Remoto, Curitiba, p. 4070-4077, 2011.

ANDRIOTTI, J.L.S. Fundamentos de Estatística e Geoestatística. São Leopoldo: Ed. UNISINOS, $2^{\text {a }}$ reimpressão, 166 p., 2005.

ASSAD, E.D.; EVANGELISTA, B.A. Análise freqüencial da precipitação Pluviométrica. In: ASSAD, E.D. et al., Chuva nos Cerrados: Análise e Espacialização. Brasília: EMBRAPA-SPI, Cap. II, p. 25-41, 1994.

BÁRDOSSY, A.; PEGRAM, G. Infilling missing precipitation records - A comparison of a new copula-based method with other techniques. J. Hidr., v. 519, Part. A, p. 1162-1170, 2014.

BATISTA, M.L.; COELHO, G.; TEIXEIRA, M.B.R.; OLIVEIRA, M.S. S. Estimadores de semivariância: análise de desempenho no mapeamento da precipitação anual para o estado de minas gerais. Rev. Sci. Agr., v. 19, n. 1, p. 64-74, 2018.

BAUMGARTNER, M.F.; APFL, G.M. Remote sensing and geographic information systems. Hydrological Sciences Journal, v. 41, n. 4, p. 592-607, 1996.

BERTONI, J.C.; TUCCI, C.E.M. Precipitação. In.: TUCCI, C.E.M. (ed) Hidrologia: Ciência e Aplicação. Porto Alegre: UFRGS, p. 177-241, 2007.

BIER, A.A; FERRAZ, S.E.T. Comparação de metodologias de preenchimento de falhas em dados meteorológicos para estações no Sul do Brasil. Rev. Bras. Met, v. 32, n. 2, p. 215-226, 2017.

BORGES, P.A.; FRANKE, J.; ANUNCIAÇÃO, Y.M.T.; WEISS, H.; BERNHOFER, C. C. Comparison of spatial interpola- tion methods for the estimation of precipitation distribution in Distrito Federal, Brazil. Theoretical and Applied Climatology Journal, v. 123, p. 335-348, 2016.

BOSER, B.E.; GUYON, I.M.; VAPNIK, V.N. A training algorithm for optimal margin classifiers. In: $V$ Workshop on Computational Learning Theory, Pittsburgh, Pennsylvania, p. 144-152, 1992.

BRUBACHER, J.P.; OLIVEIRA, G.G.; GUASSELLI, L.A. Identificação e análise de eventos extremos de precipitação na bacia hidrográfica do rio dos Sinos/RS. In: I Congresso Brasileiro Sobre Desastres Naturais, Rio Claro, 2012.

BURROUGH, P.A. Principals of Geographical Information Systems for Land Resources Assessment. Oxford: Clarendon Press, 194 p., 1986.

CARUSO, C.; QUARTA, F. Interpolation Methods Comparison. Computers Math. Appl., v. 35, n. 12, p. 109-126, 1998.

CARVALHO, J.R.P de; ASSAD, E.D. Análise espacial da precipitação pluviométrica no estado de São Paulo: Comparação de métodos de interpolação. Rev. Eng. Agríc., v. 25, n. 2, p. 377-384, 2005.

CARVALHO, J.R.P. de; QUEIROZ, E.F. de. Uso de cokrigagem colocalizada na determinação da distribuição espacial de precipitação. Boletim Técnico, EMBRAPA, 2002.

CASTRO, F.; PEZZOPANE, J.E.M.; CECÍLIO, R.A.; PEZZOPANE, J.R.M.; XAVIER, A.C. C. Avaliação do desempenho dos diferentes métodos de interpoladores para parâmetros do balanço hídrico climatológico. Rev. Bras. Eng. Agríc. e Ambient., v. 14, n. 8, p. 871-880. 2010.

CECÍLIO, R.A.; PRUSKI, F.F. Interpolação dos parâmetros da equação de chuvas intensas com uso do inverso de potências da distância. Rev. Bras. Eng. Agríc. e Ambient., v. 7, n. 3, p. 501-504, 2003.

CERRI, R.; CARVALHO, A.C.P.L.F. Aprendizado de máquina: breve introdução e aplicações. Cadernos de Ciência \& Tecnologia, v. 34, n. 3, p. 297-313, 2017.

COLLISCHONN, B.; ALLASIA, D.; COLLISCHONN, W.; TUCCI, C.E.M. M. Desempenho do satélite TRMM na estimativa de precipitação sobre a bacia do Paraguai Superior. Rev. Bras. Cart., v. 59, n. 1, p. 93-99, 2007.

COULIBALY, M.; BECKER, S. Spatial interpolation of annual precipitation in South Africa - Comparison and evaluation of methods. J. Wat. Inter., v. 32, n. 3, p. 494-502, 2009.

CORREIA, T.P.; DOHLER, R.E.; DAMBROZ, C.S.; BINOTI, H.B. Aplicação de redes neurais artificiais no preenchimento de falhas de precipitação mensal na região serrana do Espírito Santo. Revista Geociências, v. 35, n. 4, p. 560-567, 2016.

CREPANI, E.; MEDEIROS J.S. Imagens Fotográficas Derivadas de MNT do Projeto SRTM para Fotointerpretação na Geologia, Geomorfologia e Pedologia. São José dos Campos: INPE, 40 p., 2004.

CREUTIN, J.D.; OBLED, C. Objetive analysis and mapping techniques for rainfalls fields: An objetive comparison. Water Resources Research, v. 18, n. 2, p. 413-431, 1982.

DEPINÉ. H.; CASTRO, N.M.R.; PINHEIRO, A.; PEDROLLO, O. O. Preenchimento de falhas de dados horários de precipitação utilizando redes neurais artificiais. Rev. Bras. Rec. Hídr., v. 19, n. 1, p. 51-63, 2014.

DIRKS, K.N.; HAY, J.E.; STOW, C.D.; HARRIS, D. High-resolution studies of rainfall on Norfolk Island Part II: Inter- 
polation of rainfall data. J. Hidr., v. 208, n. 3-4, p. 187-193, 1998.

DORNELLES, F.; GOLDENFUM, J.A.; PEDROLLO, O.C. Artificial neural network methods applied to forecasting river levels. Rev. Bras. Rec. Hídr., v. 18, n. 4, p. 45-54, 2013.

FERRÃO, M.F.; MELLO, C.; BORIN, A.; MARETTO, A.; POPPI, R.J. J. LS-SVM: Uma nova ferramenta quimiométrica para regressão multivariada, comparação de modelos de regressão LS-SVM e PLS na quantificação de adulterantes em leite em pó empregando NIR. Revista Química Nova, v. 30, n. 4, p. 852-859, 2007.

FIBBI, L.; CHIESI, M.; MORIONDO, M.; BINDI, M.; CHIRICI, G.; PAPALE, D.; GOZZINI, B.; MASELLI, F. F. Correction of a $1 \mathrm{~km}$ daily rainfall dataset for modelling forest ecosystem processes in Italy. Meteorological Applications, v. 23, n. 2, p. 294-303, 2016.

FONSECA, J.S.; MARTINS, G.A.; TOLEDO, G.L. Estatística Aplicada. 2. ed. São Paulo: Atlas, 267 p., 2012.

FREITAS, G.M.; PAPA, J.P.; AVILA, A.M.H.; FALCÃO, A.X.; PINTO, H.S. S. Estimativa de ocorrência de precipitação em áreas agrícolas utilizando floresta de caminhos ótimos. Rev. Bras. Met., v. 25, n. 1, p. 13-23, 2010.

FRENCH, M.N.; KRAJEWSKI, W.F.; CUYKENDAL, R.R. Rainfall forecasting in space and time using a neural network. J. Hidr., v. 1367, n. 1-4, p. 1-37, 1992.

GARDIMAN JUNIOR, B.S.; MAGALHÃES, I.A.L.; FREITAS, C.A.A. A. CECÍLIO, R.A. Análise de técnicas de interpolação para espacialização da precipitação pluvial na bacia do rio Itapemirim (ES). Revista Ambiência, v. 8, n. 1, p. 61-71, 2012.

GIACOMIN, G.; CARVALHO, M.B.; SANTOS, A.P.; MEDEIROS, N.C.; FERRAZ, A.S. S. Análise comparativa entre métodos interpoladores de modelos de superfícies. Rev. Bras. Cart., v. 66, n. 6, p. 1315-1329, 2014.

GIMENEZ, D.F.S. Análise da Precipitação Pluvial e Ocorrências de Desastres Naturais no Estado de São Paulo (1976-2012). Dissertação de Mestrado em Geografia, Universidade Estadual de Campinas, Campinas, 98 p., 2017.

GONG, G.; MATTEVADA, S.; O'BRIANT, S. Comparison of the accuracy of kriging and IDW interpolations in estimating groundwater arsenic concentrations in Texas. Environ. Res., v. 130, p. 59-69, 2014.

GOOVAERTS, P. Geostatistics for Natural Resources Evaluation. New York: Oxford University, 496 p., 1997.

GROISMAN, P.Y.; LEGATES, D.R. The accuracy of united states precipitation data. Bulletin of the American Meteorological Society, v. 75, n. 3, p. 215-298, 1993.

GUARNIERI, R.A. Emprego de Redes Neurais Artificiais e Regressão Linear Múltipla no Refinamento das Previsões de Radiação Solar do Modelo ETA. Dissertação de Mestrado em Meteorologia, Instituto Nacional de Pesquisas Espaciais (INPE), São José dos Campos, 171 p., 2006.

GUIMARÃES, G.M.; FINCK, J.S.; MARCUZZO, F.F.N. Espacialização pluviométrica da precipitação média mensal na parte brasileira da bacia do rio Uruguai. In: XXIX Congresso Brasileiros de Engenharia Sanitária e Ambiental, Congresso ABES-FENASAN, São Paulo, p. 1-11, 2017.

GUNDOGDU, I.B. Usage of multivariate geostatistics in interpolation processes for meteorological precipitation maps.
Theoretical and Applied Climatology, v. 127, n. 1-2, p. 81-86, 2017.

GUPTA, N. Artificial neural network. Network and Complex Systems, v. 3, n. 1, p. 24-28, 2013.

HAYKIN, S.O. Neural Networks and Learning Machines. $3^{\text {a }}$ ed. Upper Saddle River: Prentice Hall, 906 p., 2008.

HAYLOCK, M.R.; HOFSTRA, N.; KLEIN TANK, A.M.G.; KLOKE.J.; JONES, P.D.; NEW, M. M. A European daily high-resolution gridded data set of surface temperature and precipitation for 1950-2006. J. Geophys.I Res., v. 113, D20119, 2008.

HENRICHS, M.; STEINBRICH, A.; LEISTERT, H.; SCHERER, I.; SCHUETZ, T.; UHL, M.; WEILER, M. M. Model Based Estimation of a Natural Water Balance as Reference for Planning in Urban Areas. In: XI International Conference on Urban Drainage Modelling, Palermo, p. 953-957, 2018.

HOU, A.Y.; KAKAR, R.K.; NEECK, S; AZARBARZIN, A.; KUMMEROW, C.D.; KOJIMA, M.; OKI, R.; NAKAMURA, K.; IGUCHI, T. T. The global precipitation measurement mission. Bull. Amer. Meteor. Soc., v. 95, n. 5, p. 701-722, 2014.

HUFFMAN, G.J.; ADLER, R.F.; BOLVIN, D.T.; NELKIN, E.J. The TRMM Multi-satellite Precipitation Analysis (TMPA). In: Satellite Rainfall Applications for Surface Hydrology, Dordrecht, p. 3-22, 2010.

HU, Z.; HU, Q, ZANGH, C., CHEN, X, Li, Q. Evaluation of reanalysis, spatially interpolated and satellite remotely sensed precipitation data sets in central Asia. J. of Geophys. Res., v. 121, n. 10, p. 5648-5663, 2016.

ISAAKS, E.H.; SRIVASTAVA, R.M. Applied Geostatistics. New York: Oxford University Press, 561 p., 1989.

JAVARI, M. Comparison of interpolation methods for modeling spatial variations of precipitation in Iran. International Journal of Environmental e Science Education, v. 12, n. 5, p. 1037-1054, 2017.

JUNIOR, H.N.; VANZELA, L.S. Influência do relevo sobre a distribuição espacial da precipitação no Araguatatuba - SP. In: XII Simpósio Brasileiro de Climatologia Geográfica, Goiânia, p. 2011-2024. 2016.

KIM, J.; RYU, J.H. A Heuristic Gap Filling Method for Daily Precipitation Series. Water Ressources Management, v. 30, n. 7, p. 2275-2294, 2016.

KUMMEROW, C.; SIMPSON, J.; THIELE, O.; BARNES, W.; CHANG, A.T.C. C. et al. The status of the Tropical Rainfall Measuring Mission (TRMM) after two years in orbit. Journal of Applied Meteorology, v. 39, n. 12, p. 19651982, 2000.

LAM, N.S. Spatial interpolation methods: A review. The American Cartographer, v. 2, n. 10, p. 129-149, 1983.

LANCASTER, P., SALKAUSKAS, K. An Introduction to Curve and Surface Fitting. Unpublished, Division of Applied Mathematics, University of Calgary, 114 p, 1975.

LANÇA, R. Desenvolvimento de um modelo hidrológico de superfície à escala da bacia hidrográfica. TecnoVisão, v. 16, p. 1-10, 2004.

LANDIM, P.M.B. Introdução aos Métodos de Estimação Espacial para Confecção de Mapas. UNESP/Rio Claro: Laboratório de Geomatemática, Texto Didático 02, 20 p., 2000. 
LEDRA, L. Métodos de Preenchimento de Falhas de Dados Pluviométricos: Comparações Para Dados de 24 Horas na Cidade de Joinville, SC. Dissertação de Mestrado em Engenharia Civil, UESC, Joinvile, 157 p., 2017.

LEIVAS, J.F.; BERLATO, M.A.; FONTANA, D.C. Risco de deficiência hídrica decendial na metade sul do Estado do Rio Grande do Sul. Rev. Bras. Eng. Agríc. e Ambient., v. 10, n. 2, p. 397-407, 2006.

LI, M.; SHAO, Q.; ZHANG, L.; CHIEW, F.H.S. A new regionalization approach and its application to predict flow duration curve in ungauged basins. J. hidr., v. 389, n. 1-2, p. 137-145, 2010.

LIMA, C.A.M. Comitê de Máquinas: Uma abordagem Unificada Empregando Máquinas de Vetores de Suporte. Tese de Doutorado em Engenharia Elétrica, Universidade Estadual de Campinas, Campinas, SP, 378 p., 2004.

LY, S.; CHARLES, C.; DEGRÉ, A. Different methods for spatial interpolation of rainfall data for operational hydrology and hydrological modeling at watershed scale: A review. Biotechnol. Agron. Soc. Environ, v, 17, n. 2, p. 392-406, 2013.

MACHADO R. E. Simulação de Escoamento e de Produção de Sedimentos em uma Microbacia Hidrográfica Utilizando Técnicas de Modelagem e Geoprocessamento. Tese de Doutorado em Agronomia, Piracicaba, 166 p., 2002.

MALFATTI, M.G.L.; CARDOSO, A.O.; HAMBURGUER, D.S. Modelo empírico linear para previsão de vazão de rios na usina hidrelétrica de Itaipu - Bacia do Rio Paraná. Rev. Bras. Met., v. 33, n. 2, p. 257-268, 2018.

MARCUZZO, F.N; ANDRADE, L. R.; MELO, D.C.R. Métodos de interpolação matemática no mapeamento de chuvas do estado do Mato Grosso. Rev. Bras. Geog. Fís., v. 4, n. 4, p. 793-804, 2011.

MARCUZZO, F. Mapas da espacialização trimestral de chuva e hietrograma trimestral da região metropolitana de Teresina/ PI. In: XIX Simpósio Brasileiro de Sensoriamento Remoto, Santos, p. 515-518, 2019.

MEKANIK, F.; IMTEAZ, M.A.; GATO-TRINIDAD, S.; ELMAHDI, A. Multiple regression and artificial neural network for long-term rainfall forecasting using large scale climate modes. J. hidr., v. 503, p. 11-21, 2013.

MATEUS, R.S. Modelo Hidrológico da Bacia Hidrográfica da Represa Guarapiranga. Dissertação de Mestrado em Geografia Física, USP, São Paulo, 154 p., 2006.

MAZZINI, P.L.F.; SCHETTINI, C.A.F. Avaliação de metodologias de interpolação espacial aplicadas a dados hidrográficos costeiros quasesinóticos. Brazilian Journal of Aquatic Science and Technology, v. 13, n. 1, p. 53-64, 2009.

MEDINA, A.S; QUINTAS, M.C.L. O método de interpolação de curvatura mínima. II Simpósio Brasileiro de Ciências Geodésicas e Tecnologias da Geoinformação, Recife, 2008.

MEKIS, E.; DONALDSON, N.; REID, J.; ZUCCONI, A.; JEFFERY, H.; LI, Q.; NITU, R.; MELO, S. S. An overview of surface-based precipitation observations at environment and climate change Canada. Atmosphere-Ocean, v. 56, n. 2, p. 71-95, 2018.

MELO, H.A.; CUNHA, J.E.B.L.; NÓBREGA, R.L.B.; RUFINO, I.A.A.; GALVÃO, C.O. O. Modelos Hidrológicos e
Sistemas de Informação Geográfica (SIG): Integração Possível. In: IX Simpósio de Recursos Hídricos do Nordeste, Salvador, p. 1-14, 2008.

MELLO, C.R.; SILVA, A.M. Modelagem estatística da precipitação mensal e anual e no período seco para o estado de Minas Gerais. Rev. Bras. Eng. Agríc. e Ambient., v. 13, n. 1, p .68-74, 2009.

MORALES, R.A.V.; ARAUJO, C.E.S. Avaliação e comparação de dois métodos de qualificação de dados diários de precipitação no Estado de Santa Catarina. Rev. Bras. Met., v. 32, n. 1, p. 65-75, 2017.

MOREIRA, A.; FONTANA, D.C.; KUPLICH, T.M.; CARDOSO, M.A. Dados meteorológicos estimados em condições de clima subtropical e a relação com índices de vegetação. Rev. Bras. Cart, v. 70, n. 4, p. 1409-1436, 2017.

NAGHETTINI, M.; PINTO, E.J. de A. Hidrologia Estatística. Belo Horizonte: CPRM, 552 p., 2007.

OLIVEIRA, V.P.S., ZANETTI, S.S., PRUSKI, F.F. CLIMABR Parte I: Modelo para a geração de séries sintéticas de precipitação. Rev. Bras. Eng. Agríc. e Ambient., v. 9, n. 3, p. 348-355, 2005.

OLIVEIRA, L.F.C.; FIOREZE, A.P.; MEDEIROS, A.M.M.; SILVA, M.A.S. S. Comparação de metodologias de preenchimento de falhas de séries históricas de precipitação pluvial anual. Rev. Bras. Eng. Agríc. e Ambient, v. 14, n. 11, p. 1186-1192, 2010.

OLIVEIRA, G.G.; PEDROLLO, O.C.; CASTRO, N.M.R. Simplifying artificial neural network models of river basin behaviour by an automated procedure for input variable selection. Engineering Applications of Artificial Intelligence, v. 40, p. 47-61, 2015.

PAZ, A.R. Simulação Hidrológica de Rios com Grandes Planícies de Inundação. Tese de Doutorado, Programa de Pós-Graduação em Recursos Hídricos e Saneamento Ambiental, UFRGS, Porto Alegre, 258 p., 2010.

PETTY, G.W. The status of satellite-based rainfall estimation over land. Remote Sensing of Environment, v. 51, n. 1, p. 125-137, 1995.

PHILLIPS, D.L.; DOLPH, J.; MARKS, D. A comparison of geostatistical procedures for spatial analysis of precipitations in mountainous terrain. Agriculture and Forest Meteorology, v. 58, n. 1-2, p. 119-141, 1992.

RAGHAVENDRA, A.; DAI, A.; MILRAD, S.M.; CLOUTIERBISBEE, S.R. R. Floridian heatwaves and extreme precipitation: future climate projections. Climate Dynamics, v. 52, p. 495-508, 2019.

REMACRE, A.Z.; NORMANDO, M.N.; SANCEVERO, S.S. Krigagem das proporções utilizando a krigagem da média: uma ferramenta auxiliar na modelagem de reservatórios. Rev. Bras. Geoc., v. 38 (suplemento), p. 82-87, 2008.

RUMELHART, D.E.; HINTON, G.E.; WILLIAMS, R.J. Learning representations by backpropagating errors. Nature, v. 323, p. 533-536, 1986.

SAFRE, A.L.S. Estimativa e Análise da Precipitação do Ano de 2013 na Bacia do Rio Pardo Utilizando Técnicas de Geoprocessamento. Trabalho de Conclusão de Curso de Bacharelado em Geografia, Universidade Estadual Paulista Julio de Mesquita Filho, Ourinhos, 72 p., 2015.

SANTOS, D.M. Zoneamento das Áreas Suscetíveis a Movimentos de Massa, Enxurradas e Inundações no Municí- 
pio de Sarques de Souza - RS. Trabalho de Conclusão de Curso em Bacharelado em Engenharia Ambiental, UNIVATES, Lajeado, 135 p., 2015.

SANTOS, G.G.; FIGUEIREDO, C.C. de; OLIVEIRA, L.F.C.; GRIEBELER, N.P. Intensidade-duração-frequência de chuvas para o Estado de Mato Grosso do Sul. Rev. Bras. Eng. Agríc. e Ambient., v. 13 (suplemento)., p. 899-905, 2009.

SÁRKÖZY, F. Gis functions - Interpolation. Periodica Polytechnica Engineering, v. 43. n. 1, p. 63-87, 1999.

SCHÖLKOPF, B., SMOLA, A.J. Learning with Kernels. Cambridge: MIT Press, 626 p., 2002.

SERRÃO, E.A.O.; WANZELER, R.T.S.; SANTOS, C.A; GONÇALVES, L.J.M.; LIMA, A.M.M.; ROCHA, E.J.P. P. Avaliação estatística entre as estimativas de precipitação da constelação GPM com satélite TRMM: Uma análise a bacia hidrográfica do Rio Solimões. Rev. Bras. Climat. v. 18, p. 256-275, 2016.

SIBSON, R. A brief description of natural neighbor interpolation. In: BARNETT, V. Interpreting Multivariate Data. New York: John Wiley e Sons, p. 21-36, 1981.

SILVA, J.C.; HELDWIN, A.B.; MARTINS, F.B.; TRENTIN, G.; GRIMM, E.L. L. Análise de distribuição de chuva para Santa Maria, RS. Rev. Bras. Eng. Agríc. e Ambient., v. 11, n. 1, p. 67-72, 2007.

SILVA, R.M.; PEREIRA E SILVA, L.; MONTENEGRO, S.M.G.L.; SANTOS, C.A.G. G. Análise da variabilidade espaço-temporal e identificação do padrão da precipitação na bacia do Rio Tapacurá, Pernambuco. Sociedade e Natureza, v. 22, n. 2, p. 357-372, 2010.

SILVA, V.S.V. Estimativa de Precipitação Pontual em Diferentes Escalas para uso em Modelo Concentrado Chuva-Vazão. Dissertação de Mestrado em Recursos Hídricos e Saneamento Ambiental, UFRGS, Porto Alegre, 139 p., 2011.

SMITH, M.J.; GOODCHILD, M.F.; LONGLEY, A.P. Geospatial Analsys: A Comprehensive Guide to Principles, Techniques and Software Tools. Licester:Troubador Publishing Ltd, 3. ed., 516 p., 2009.

SOARES, A. Geoestatística Aplicada às Ciências da Terra e do Ambiente. Lisboa: IST-PRESS, $3^{\text {a }}$ ed., 206p., 2000.

SOUSA, W.S.; SOUSA, F.A.S. Rede neural artificial aplicada à previsão de vazão da Bacia Hidrográfica do Rio Piancó. Rev. Bras. Eng. Agríc. Ambient, v. 14, n. 2, p.173-180, 2010.

SOUZA J.L.L.L.; GOMES，T.S.; DIAS，R.S.; OLIVEIRA, G.M.A.; SANTOS, R.L. L. Avaliação de métodos de interpolação aplicados à espacialização das chuvas no território identidade Portal do Sertão/Bahia. XV Simpósio Brasileiro de Sensoriamento Remoto, Curitiba, p. 4295-4302, 2011.

SOUZA, A.; SANTOS, D.A.S.; ARISTONE, F.; KOVA-ANDRI, E.; MATASOVI, B.; PIRES, J.C.; IKEFUTI, P.V.V. Impacto de fatores meteorológicos sobre as concentrações de ozônio modelados por análise de séries temporais e métodos estatísticos multivariados. Revista Holos, v. 5, p. 2-16, 2017.

SULAIMAN, J.; WAHAB, S.H. Heavy rainfall forecasting model using artificial neural network for flood prone area. IT Convergence and Security, v. 449, p. 68-76, 2018.
THOMPSON, S.K. Sampling. New York: Interscience Publication, 343 p., 1992.

TRENBERTH, K.E. Changes in precipitation with climate change. Climate Research, v. 47, p. 123-138, 2011.

TUCCI, C.E.M. Regionalização de Vazão. Porto Alegre: UFRGS, 256p., 2002.

TUCCI, C.E.M. Hidrologia: Ciência e Aplicação, $4^{a}$ ed., Porto Alegre: ABRH/Editora UFRGS, 944 p., 2009.

UMEHARA, S.; YAMAZAKI, T.; SUGAI, Y.A. Precipitation estimation system based on support vector machine and neural network. In: Electronics and Communications in Japan, Part. 3: Fundamental Electronic Science, v. 89, n. 3, p. 38-47, 2006.

VALENÇA, M.J.S. Análise e Projeto de Redes Neurais com Abordagem Construtiva para Modelagem de Sistemas Complexos. Tese de Doutorado em Ciências da Computação, UFP, Recife, 223 p., 1999.

VALENTE, A.L.S. Desenvolvimento de uma Metodologia para Planejamento Urbano, Utilizando Técnicas de Sensoriamento Remoto, Modelagem Numérica do Terreno (MNT) e Sistema de Informações Geográficas (SIG). Dissertação de Mestrado em Sensoriamento Remoto, UFRGS, Porto Alegre, 200 p, 1995.

VESPUCCI, A.G.; SANTOS, J.G.R.; BAYER, M. Estações fluviométricas do estado de Goiás: qualificação dos dados hidrológicos disponíveis na base HIDROWEB/ANA. Revista Ateliê Geográfico, v. 10, n. 3, p. 89-108, 2016.

VIEIRA, S.R. Geoestatística em estudos de variabilidade espacial do solo. In: NOVAIS, R.F et al. Tópicos em Ciência do Solo. Viçoas: Sociedade Brasileira de Ciência do Solo, p.1-53, 2000.

VILLAZÓN, M.F.; WILLEMS, P. Filling gaps and daily disaccumulation of precipitation data for rainfall-runoff model. In: IV International Scientific Conference on Water Observation and Information Systems for Decision Support, Ohrid, Republic of Macedonia, 2010.

VIOLA M.R.; MELLO, C.R.; ACERBI JR., F.W.; SILVA, A.M. Modelagem hidrológica na bacia hidrográfica do Rio Aiuruoca, MG. Rev. Bras. Eng. Agríc. Ambient, v. 13, n. 5, p. $581-590,2009$.

VIOLA, M.R.; MELLO, C.R.; PINTO, D.B.F.; MELLO, J.M.; ÁVILA, L.F. F. Métodos de interpolação espacial para o mapeamento da precipitação pluvial. Rev. Bras. Eng. Agríc. Ambient., v. 14, n. 9, p. 970-978, 2010.

WAGNER, P.D.; FIENER, P.; WILKJEN, F.; KUMAR, S.; CHNEIDER, K. K. Comparison and evaluation of spatial interpolation schemes for daily rainfall in data scarce regions. J. Hydr., v. 464, p. 388-400, 2012.

WATSON, D. The natural neighbor series manuals and source codes. Computers e Geosciences, v. 25, n. 4, p. 463-466, 1999.

WEIGEND, A. S.; MANGEAS, M.; SRISTAVA, A. N. Nonlinear gated experts for time series: Discovering regimes and avoiding over fitting. International Journal of Neural Systems, v. 6, n. 4, p. 373-399, 1995.

WIDROW, B.; HOFF, M.E. Adaptive Switching Circuits. New York: Ire Wescon Convention Record, p. 96-104, 1960.

XU, W.; ZOU, Y.; ZHANG, G.; LINDERMAN, M. A comparison among spatial interpolation techniques for daily rain- 
fall data in Sichuan Province, China. Int. J. Clim., v. 35, n. 10, p. 2898-2907, 2015.

YANG, X.; XIE, X.; LIU, D.L.; JI, F.; WANG, L. Spatial interpolation of daily rainfall data for local climate impact assessment over greater Sydney region. Advances in Meteorology, v. 2015, p. 1-12, 2015.

ZANATA, D.R.F. Desenvolvimento de Sensor Virtual Empregando Redes Neurais Para Medição da Composição em Coluna de Destilação. Dissertação de Mestrado, Escola Politécnica da USP, 209 p., 2005.

ZEILHOFER, P.; LIMA, E.B.R.; SANTOS, F.M.; RIGO JÚNIOR, L.O. O. Um ambiente SIG para modelagem integrada da qualidade da água utilizando QUAL2e. Revista Caminhos da Geografia, v. 4, n. 10, p. 107-125, 2003.

WANDERLEY, H.S.; AMORIM, R.F.C.; CARVALHO, F.O. Variabilidade espacial e preenchimento de falhas de dados pluviométricos para o estado de Alagoas. Rev. Bras. Met., v. 27, n. 3, p. 347-354, 2012.

WATSON, D.F., PHILIP, G.M. A refinement of inverse distance weighted interpolation. Geoprocessing, v. 2, n. 4, p. 315$327,1985$.
WILKS, D.S. Statistical Methods in the Atmospheric Sciences. International Geophisics Series, v. 91, 2. ed., Philadelphia, Elsevier Academic Press Publications, 649 p., 2006.

ZAREKARIZI, M.; RANA, A.; MORADKHANI, H. Precipitation extremes and their relation to climatic indices in the Pacific Northwest USA. Climate Dynamics, v. 50, n. 11, p. 4519-4537, 2018.

ZHAO, Y.; YANG, Z.; WEI, Y.; HU, B; CAO, Q.; TONG, K.; LIANG, Y. Y. Eight hundred years of drought and flood disasters and precipitation sequence reconstruction in Wuzhou City, Southwest China. Water, v. 11, n. 219, p. 1-11, 2019.

ZHOU, Y.; LAU, W.K.M.; HUFFMAN, G.J. Mapping TRMM TMPA into average recurrence interval for monitoring extreme precipitation events. J. Appl. Climatology, v. 54, p. $979-995,2015$.

License information: This is an open-access article distributed under the terms of the Creative Commons Attribution License (type CC-BY), which permits unrestricted use, distribution and reproduction in any medium, provided the original article is properly cited. 